\title{
Dermoscopic Patterns in Relation to the Clinicopathologic Manifestations of Leprosy
}

\author{
Mia Katrina R. Gervasio, MD, MRes, Sarah Faye V. Obbus, MD, Marie Len A. Camaclang-Balmores, MD, \\ Arunee H. Siripunvarapon, MD and Belen L. Dofitas, MD, PhD \\ Department of Dermatology, Philippine General Hospital, University of the Philippines Manila
}

\begin{abstract}
Objectives. Leprosy is a chronic granulomatous infection caused by the obligate intracellular organism Mycobacterium leprae. Current diagnostic tests for confirmation and treatment monitoring such as slit skin smear and biopsy are invasive and require time for processing, reading, and interpretation. Dermoscopy is a technique that allows the visualization of structures not readily seen by the naked eye. It can be performed at the point of care, providing a non-invasive link between clinical and histopathologic examination. This study aimed to determine the dermoscopic findings and associated clinicopathologic findings of the different forms of leprosy.

Methods. A cross-sectional study was conducted. All new and follow-up patients aged 19 years old and above clinically diagnosed with leprosy were invited to participate in the study during the three-month investigation period. Clinical and dermoscopic photographs of representative skin lesions were taken, and a review of slit skin smear and histopathology results was done. Data analysis was performed using Stata SE version 13. The association between dermoscopic findings and the following parameters: anatomic location, Ridley-Jopling classification, WHO classification, treatment duration, and average bacteriologic index were analyzed using Fisher's exact test. The level of significance was set at $5 \%$.

Results. A total of 57 lesions were included. Linear vessels $(p=0.031)$, structureless areas $(p=0.008)$, and globules $(p=0.002)$ were found to be significantly associated with the anatomic location. Decreased hair was found to be significantly associated with treatment duration $(p=0.038)$. No significant associations were found between dermoscopic findings and Ridley-Jopling classification, WHO classification, and ABI. Eight biopsies taken at the time of dermoscopy were reviewed, with all sites showing structureless or globular areas corresponding to the presence of granulomas on histopathology (100\%). No other notable associations were observed.

Conclusion. Dermoscopy is a potentially useful tool to aid in the diagnosis and treatment monitoring of leprosy. Limitations of this study include the small sample size, the preponderance of subjects in the lepromatous pole, and assessments by a single trained dermoscopist. A longer study duration including a larger number of newly diagnosed leprosy patients is recommended.
\end{abstract}

Key Words: leprosy, Hansen's disease, dermoscopy

\section{INTRODUCTION}

Leprosy, otherwise known as Hansen's disease, is a chronic granulomatous infection caused by Mycobacterium leprae. The disease principally affects the skin and peripheral nerves and may result in permanent physical deformity. Worldwide, leprosy continues to be a considerable public health problem, being the leading cause of permanent Corresponding author: Mia Katrina R. Gervasio, MD, MRes Department of Dermatology Philippine General Hospital University of the Philippines Manila Taft Avenue, Ermita, Manila 1000, Philippines Email:mrgervasio@up.edu.ph physical disability among communicable diseases. ${ }^{1-3}$

Following the recommendations of the World Health Organization (WHO) Expert Committee on Leprosy, a case of leprosy presents with at least one of the three cardinal signs: (1) reddish or hypopigmented skin lesions 
with accompanying loss of sensation, (2) peripheral nerve involvement manifesting as enlarged or thickened nerves with associated loss of sensation, and/or (3) a positive slit skin smear with acid-fast bacilli. ${ }^{2}$

While leprosy remains endemic to the Philippines, early recognition of the clinical signs and symptoms of the disease remains key in preventing significant morbidity and mortality. ${ }^{1-3}$ Current diagnostic tests for its confirmation such as slit skin smear and skin biopsy are invasive and require time for processing, reading, and interpretation. In areas where ancillary testing is unavailable, diagnosis and treatment monitoring is then solely reliant on accurate clinical assessment and examination.

Dermoscopy, otherwise known as surface microscopy or epiluminescent microscopy, is a technique that allows the enhanced visualization of cutaneous lesions. Structures present at the epidermis, the dermoepidermal junction, and the papillary dermis up to the starting edge of the reticular dermis may be seen with a 10- to 70-fold magnification depending on the type of dermoscope used. It is a noninvasive diagnostic tool used for rapid in vivo evaluation of morphologic structures not readily seen by the naked eye. It is light and portable, and acquired images may be stored in a digital camera or smart phone allowing the review of images. It has been found to correlate well with histopathologic findings, providing a non-invasive link between clinical and histopathologic examination..$^{4-6}$

While the use of dermoscopy has expanded in recent years to inflammatory and infectious conditions, studies on the dermoscopic findings in leprosy remain scarce. ${ }^{7-13}$ Thus, a study on the dermoscopic findings associated with the different forms of leprosy in both newly diagnosed and treated cases may expand the utility of the technique to aid not only in its diagnosis but also in monitoring response to treatment.

This study, therefore, aimed to determine the dermoscopic findings associated with the following parameters: (1) anatomic location, (2) Ridley-Jopling classification, (3) WHO classification, (4) treatment duration, and (5) average bacteriological index (ABI). In addition, this study also aimed to describe the association between dermoscopic findings and histopathologic features in the different forms of leprosy.

\section{METHODS}

\section{Study Design and Population}

A cross-sectional study was conducted, and convenience sampling was done. All patients aged 19 years and above who consulted the dermatology outpatient clinic of the Philippine General Hospital during the three-month investigation period from September to November 2018 were invited to participate in the study. All patients must have been clinically diagnosed with leprosy and signed an informed consent form. Patients were excluded if they have used topical or systemic corticosteroids within 30 days.

\section{Data Collection}

Standard medical photographs of each lesion were taken using a digital camera (Sony DSC-RX100 II, Sony Electronics Inc., San Diego, CA, USA, with 20.2 megapixels). Demographic data including age, sex, and anatomic location of the selected lesions were taken. Chart review was done to obtain information on the clinical classification, treatment status, slit skin smear, and average bacteriological index. Skin biopsies taken at the time of dermoscopy from eight subjects were also reviewed.

\section{Dermoscopy}

Dermoscopy was performed using a DermLite DL4 dermoscope (3Gen Inc., 31521 Rancho Viejo Road, Suite 104 San Juan Capistrano, CA 92675, USA). Ultrasound gel was used as an interface medium to preserve vessel morphology and ensure better visualization. A digital camera (Sony DSC-RX100 II, Sony Electronics Inc., San Diego, CA, USA, with 20.2 megapixels) was attached to capture the images. Dermoscopic patterns were then analyzed by a trained dermoscopist (A.S.) and recorded.

\section{Statistical Analysis}

Data analysis was performed using Strata SE version 13. Quantitative variables were summarized as mean and standard deviation, while qualitative variables were tabulated as frequency and percentage. Association between dermoscopic findings and the following parameters: anatomic location, type of leprosy (Ridley-Jopling and WHO classifications), average bacteriologic index, and treatment duration were analyzed using Fisher's exact test. The level of significance was set at $5 \%$.

\section{Ethical Considerations}

The study was conducted following the guidelines of the Helsinki Declaration, and was submitted to the University of the Philippines Manila Review and Ethics Board (CODE: 2018-0397). Anonymity and confidentiality of all gathered data were ensured.

\section{RESULTS}

A total of 42 patients were included in the study (Table 1 ). The mean (SD) age was $38.8 \pm 13.3$ years, (range, 19 to 72). There was a 5:1 male to female ratio with 35 males and 7 females. Most of the patients included were classified as lepromatous (66.7\%), and the majority were classified as multibacillary (92.9\%). The mean average bacteriologic index was $0.6 \pm 0.8$, and the mean duration of treatment was $9.4 \pm 6.8$ months. The most representative lesions were selected, with most dermoscopic images taken from the extremities (42.1\%), followed by the head (31.6\%), and finally the trunk $(26.3 \%)$. 


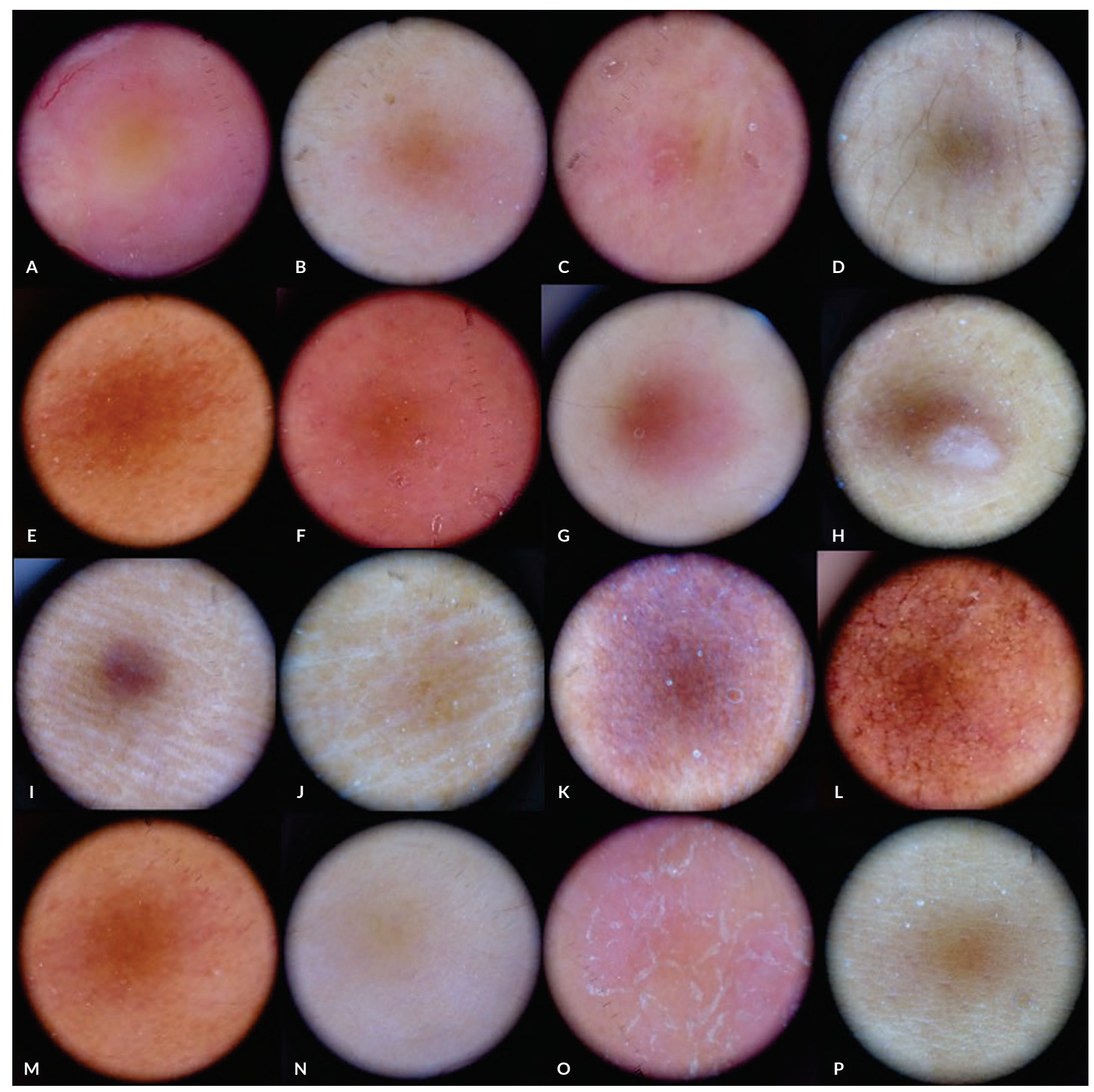

Figure 1. Dermoscopic findings observed. (A) Linear branching vessel; (B) Linear microvessel; (C) Dotted vessels; (D) Yellow-brown structureless area; (E) Brown-red structureless area; (F) Red-yellow structureless area; (G) Pink-milky red structureless area; (H) White structureless area; (I) Whitish-yellow globules; (J) Yellow globules; (K) Yellow-brown globules; (L) Brown lines; (M) Decreased hair; (N) Coiled hair; (O) Scaling; (P) Accentuated skin lines. (DermLite DL4, magnification x10).

The dermoscopic findings observed in the study were as follows: linear vessels (20 sites, $35.1 \%)$, dotted vessels (1 site, 1.8\%), branching vessels (19 sites, 33.3\%), microvessels (2 sites, 3.5\%), yellow-brown structureless areas (19 sites, $33.3 \%)$, brown-red structureless areas (1 site, $1.8 \%)$, redyellow structureless areas (2 sites, 3.5\%), pink-milky red structureless areas (4 sites, 7.0\%), white structureless areas
(1 site, 1.8\%), whitish-yellow globules (2 sites, 3.5\%), yellow globules (25 sites, $43.9 \%)$, yellow-brown globules (4 sites, 7.0\%), brown lines (8 sites, 14.0\%), decreased hair (11 sites, $1.9 \%)$, coiled hair (1 site, $1.8 \%)$, scaling (4 sites, $7.0 \%)$ and accentuated skin lines (2 sites, $3.5 \%$ ) (Figure 1 ).

The anatomic locations of the lesion were grouped under head, trunk, or extremities, with results shown in Table 2 . 
Table 1. Clinical profile of leprosy patients included in the study.

\begin{tabular}{lc}
\hline \multicolumn{1}{c}{ Clinical Data $(\mathbf{n}=42)$} & Mean \pm SD or $\mathbf{n}(\%)$ \\
\hline Age & $38.8 \pm 13.3$ \\
\hline Sex & \\
Male & $35(83.3)$ \\
Female & $7(16.7)$ \\
\hline Ridley-Jopling Classification & \\
TT & $1(2.4)$ \\
BT & $2(4.8)$ \\
BB & $6(14.3)$ \\
BL & $5(11.9)$ \\
LL & $28(66.7)$ \\
\hline WHO Classification & \\
PB & $3(7.1)$ \\
MB & $39(92.9)$ \\
\hline Treatment Duration & $9.4 \pm 6.8$ \\
$0-6$ months & $16(38.1)$ \\
$>6$ months & $26(61.9)$ \\
\hline Average Bacteriologic Index $(\mathbf{n = 3 8 )}$ & $0.6 \pm 0.8$ \\
0 & $15(39.5)$ \\
$>0$ & $23(60.5)$ \\
\hline Anatomic Location ( $=57)$ & \\
Head & $18(31.6)$ \\
Trunk & $15(26.3)$ \\
Extremities & $24(42.1)$ \\
\hline &
\end{tabular}

Table 2. Association of dermoscopic findings and anatomic location

\begin{tabular}{|c|c|c|c|c|}
\hline Dermoscopic Findings & $\begin{array}{c}\text { Head } \\
(n=18)\end{array}$ & $\begin{array}{c}\text { Trunk } \\
(n=15)\end{array}$ & $\begin{array}{c}\text { Extremities } \\
(n=24)\end{array}$ & p value \\
\hline \multicolumn{5}{|l|}{ Morphologic vascular pattern } \\
\hline Linear & $10(55.6)$ & $6(40.0)$ & $4(16.7)$ & 0.031 \\
\hline Dotted & 0 & $1(6.7)$ & 0 & 0.263 \\
\hline \multicolumn{5}{|c|}{ Arrangement of vascular structures } \\
\hline Branching & $9(50.0)$ & $5(33.3)$ & $4(16.7)$ & 0.073 \\
\hline Microvessels & $1(5.6)$ & $1(6.7)$ & 0 & 0.331 \\
\hline \multicolumn{5}{|l|}{ Colors } \\
\hline \multicolumn{5}{|l|}{ Structureless areas } \\
\hline Yellow-brown & 2 (11.1) & $5(33.3)$ & $12(50.0)$ & 0.008 \\
\hline Brown-red & $1(5.6)$ & 0 & 0 & \\
\hline Red-yellow & 0 & 0 & $2(8.3)$ & \\
\hline Pink-milky red & 0 & $2(13.3)$ & $2(8.3)$ & \\
\hline White & 0 & 0 & $1(4.2)$ & \\
\hline \multicolumn{5}{|l|}{ Globules } \\
\hline Whitish-yellow & 0 & 0 & $2(8.3)$ & 0.002 \\
\hline Yellow & $13(17.2)$ & $8(53.3)$ & $4(16.7)$ & \\
\hline Yellow-brown & $2(11.1)$ & $1(6.7)$ & $1(4.2)$ & \\
\hline Brown lines & $3(16.7)$ & $1(6.7)$ & $4(16.7)$ & 0.706 \\
\hline \multicolumn{5}{|l|}{ Follicular abnormalities } \\
\hline Decreased hair & $4(22.2)$ & $2(13.3)$ & $5(20.8)$ & 0.834 \\
\hline Coiled hair & 0 & 0 & $1(4.2)$ & 1.000 \\
\hline \multicolumn{5}{|l|}{ Others } \\
\hline Scaling & 0 & $2(13.3)$ & $2(8.3)$ & 0.281 \\
\hline Accentuated skin lines & 0 & $2(13.3)$ & 0 & 0.066 \\
\hline
\end{tabular}

There was a significant association of anatomic location with linear vessels $(p=0.031)$, structureless areas $(p=0.008)$, and globules $(\mathrm{p}=0.002)$.

Patients were divided into those who had received multi-drug therapy (MDT) for 6 months or less and those who had taken MDT for more than 6 months at the time of dermoscopy. Due to the chronic nature of leprosy, up to 6 months of therapy is unlikely to cause gross clinical or histopathologic changes in most patients. ${ }^{9,14,15}$ Decreased hair was found to be significantly associated with treatment duration $(\mathrm{p}$ value $=0.038)($ Table 3$)$.

When the dermoscopic features were analyzed according to the Ridley-Jopling classification and WHO classification, however, there were no significant associations found. Similarly, none of the dermoscopic findings were found to be significantly associated with the average bacteriologic index (ABI).

Eight biopsies taken from the site of dermoscopy were included. Dermoscopy of all sites showed structureless or globular areas with corresponding presence of granulomas on histopathology $(n=8,100 \%)$. No other notable associations were observed. A summary of dermoscopic findings and associated histopathologic findings are tabulated in Table 4. Associated clinical, dermoscopic and histopathologic pictures of selected lesions can be found in Figures 2-4.

Table 3. Association of dermoscopic findings and treatment duration

\begin{tabular}{|c|c|c|c|}
\hline Dermoscopic Findings & $\begin{array}{c}\text { 0-6 months } \\
(n=20)\end{array}$ & $\begin{array}{c}>6 \text { months } \\
(n=37)\end{array}$ & $p$ value \\
\hline \multicolumn{4}{|l|}{ Morphologic vascular pattern } \\
\hline Linear & $9(45.0)$ & $11(29.7)$ & 0.263 \\
\hline Dotted & 0 & $1(2.7)$ & 1.000 \\
\hline \multicolumn{4}{|c|}{ Arrangement of vascular structures } \\
\hline Branching & $7(35.0)$ & $11(29.7)$ & 0.263 \\
\hline Microvessels & $2(10.0)$ & 0 & 0.119 \\
\hline \multicolumn{4}{|l|}{ Colors } \\
\hline \multicolumn{4}{|l|}{ Structureless areas } \\
\hline Yellow-brown & $6(30.0)$ & $13(35.1)$ & 0.741 \\
\hline Brown-red & 0 & $1(2.7)$ & \\
\hline Red-yellow & $1(5.0)$ & $1(2.7)$ & \\
\hline Pink-milky red & $2(10.0)$ & $2(5.4)$ & \\
\hline White & $1(5.0)$ & 0 & \\
\hline \multicolumn{4}{|l|}{ Globules } \\
\hline Whitish-yellow & $1(5.0)$ & $1(2.7)$ & 0.613 \\
\hline Yellow & $9(45.0)$ & $16(43.2)$ & \\
\hline Yellow-brown & 0 & $4(10.8)$ & \\
\hline Brown lines & $1(5.0)$ & $7(18.2)$ & 0.238 \\
\hline \multicolumn{4}{|l|}{ Follicular abnormalities } \\
\hline Decreased hair & $7(35.0)$ & $4(10.8)$ & 0.038 \\
\hline Coiled hair & $1(5.0)$ & 0 & 0.351 \\
\hline \multicolumn{4}{|l|}{ Others } \\
\hline Scaling & $2(10.0)$ & $2(5.4)$ & 0.607 \\
\hline Accentuated skin lines & $2(10.0)$ & 0 & 0.119 \\
\hline
\end{tabular}



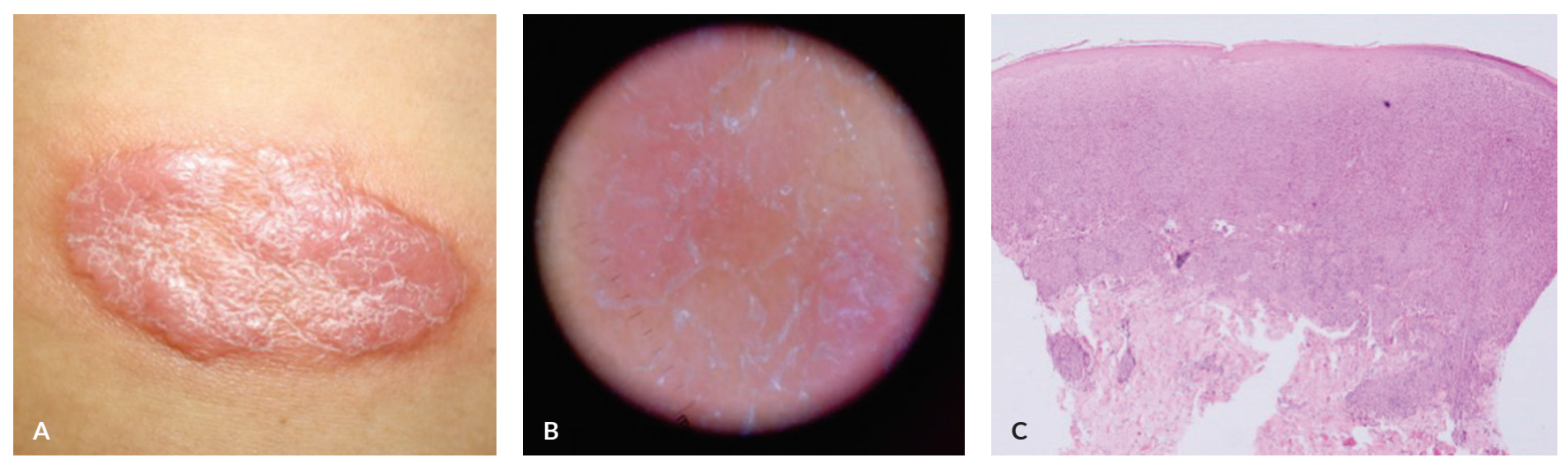

Figure 2. (A) Gross: Lesion on the trunk of a borderline lepromatous, multibacillary patient with 0 months of MDT. (B) Dermoscopic: Pink-milky red structureless areas with scaling (DermLite DL4, magnification x10) (C) Histopathologic: Atrophic epidermis, basal layer pigmentation, grenz zone, diffuse granulomatous infiltrate of lymphocytes and histiocytes with globi formation (H\&E, 4x).
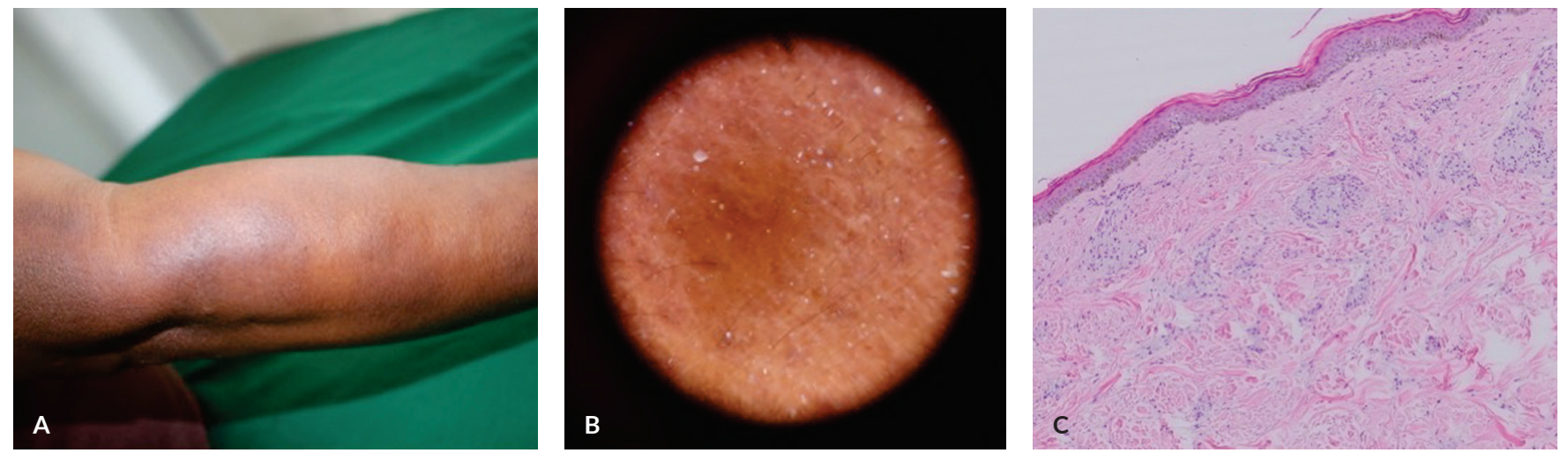

Figure 3. (A) Gross: Lesion on the right arm of a lepromatous, multibacillary patient after 12 months of MDT. (B) Dermoscopic: Yellow-brown structureless areas (DermLite DL4, magnification x10). (C) Histopathologic: Atrophic epidermis, basal layer pigmentation, nodular granulomatous infiltrate of lymphocytes and histiocytes with globi formation (H\&E, 10x).
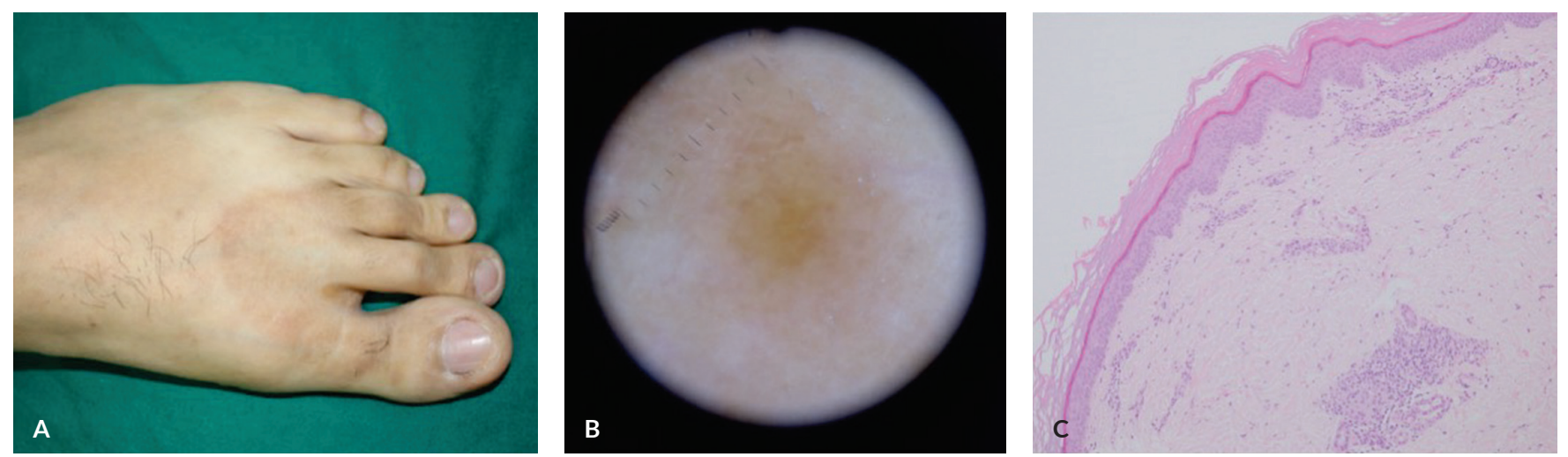

Figure 4. (A) Gross: Lesion on the right foot of a tuberculoid, paucibacillary patient after 12 months of MDT. (B) Dermoscopic: Yellow-brown structureless areas (DermLite DL4, magnification x10). (C) Histopathologic: Nodular granulomas of lymphocytes and histiocytes (H\&E, 10x). 
Table 4. Dermoscopic findings and associated histopathologic findings

\begin{tabular}{ccll}
$\begin{array}{c}\text { Subject } \\
\mathbf{1}\end{array}$ & $\begin{array}{c}\text { Site } \\
\text { Extremity }\end{array}$ & \multicolumn{1}{c}{ Dellow-brown structureless areas } & Nodular granulomas of lymphocytes and histiocytes \\
\hline $\mathbf{2}$ & Trunk & Pink-milky red structureless areas & $\begin{array}{l}\text { Atrophic epidermis, basal layer pigmentation, grenz zone, diffuse } \\
\text { granulomatous infiltrate of lymphocytes and histiocytes with globi formation }\end{array}$ \\
\hline $\mathbf{3}$ & Extremity & Yellow-brown structureless areas & $\begin{array}{l}\text { Atrophic epidermis, basal layer pigmentation, nodular granulomatous } \\
\text { infiltrate of lymphocytes and histiocytes with globi formation }\end{array}$ \\
\hline $\mathbf{4}$ & Extremity & Yellow-brown structureless areas & $\begin{array}{l}\text { Basal layer pigmentation, grenz zone, nodular and diffuse granulomatous } \\
\text { infiltrate of lymphocytes and histiocytes with globi formation }\end{array}$ \\
\hline $\mathbf{5}$ & Extremity & $\begin{array}{l}\text { Yellow globules intermingled with } \\
\text { brown lines }\end{array}$ & $\begin{array}{l}\text { Atrophic epidermis, basal layer pigmentation, nodular granulomatous } \\
\text { infiltrates of lymphocytes and histiocytes with globi formation }\end{array}$ \\
\hline $\mathbf{6}$ & Extremity & Pink-milky red structureless areas & $\begin{array}{l}\text { Basal layer pigmentation, papillary dermal edema, nodular granulomatous } \\
\text { infiltrates of lymphocytes and histiocytes with globi formation }\end{array}$ \\
\hline $\mathbf{8}$ & Extremity & Yellow-brown structureless area & $\begin{array}{l}\text { Basal layer pigmentation, nodular granulomatous infiltrates of lymphocytes } \\
\text { and histiocytes with globi formation }\end{array}$ \\
\hline & Trunk & Yellow globules & $\begin{array}{l}\text { Basal layer pigmentation, grenz zone, nodular and diffuse granulomatous } \\
\text { infiltrates of lymphocytes and histiocytes with globi formation }\end{array}$ \\
\hline
\end{tabular}

\section{DISCUSSION}

Along its immunologic spectrum, leprosy can manifest with a wide range of clinical presentations, making its diagnosis challenging. The disease remains to be a significant public health problem, especially in endemic areas. Timely diagnosis and initiation of therapy are essential components for disease control and the prevention of its complications. ${ }^{1,3}$

Dermoscopy, with its ease of use, non-invasiveness, and applicability at the point of care, can aid in the differentiation of morphologically similar conditions through the enhanced visualization of cutaneous lesions. ${ }^{4,5}$ Recently, the technique has been used to differentiate between various inflammatory and infectious diseases. The detection of yellow-orange structureless globules was reported to be suggestive of dermal granulomas which are present in conditions such as lupus vulgaris, sarcoidosis, granuloma faciale, and even leprosy. ${ }^{16-18}$

The most common dermoscopic findings encountered in this study were indeed yellow globules, yellow-brown structureless areas, and linear branching vessels as reported previously. ${ }^{5,16,18}$ Histologically, globules and structureless areas indeed correlate with dermal granulomas, with the prominence of vessels resulting from the upward displacement of the dilated structures due to the mass effect of the granuloma. ${ }^{9-12}$ When analyzed by anatomic location, the findings of linear vessels, structureless areas, and globules were significantly associated, with linear vessels and globules more commonly observed in lesions on the face. This may be due to the relative thinness of the epidermis in the area, allowing enhanced visibility of such structures. ${ }^{19}$

In the study by Ankad and Sakhare ${ }^{8}$ on 12 patients with borderline tuberculoid (BT) leprosy, the most common dermoscopic findings were white areas (100\%), decreased hair, yellow globules (66.6\%), decreased white dots (50\%), and branching vessels (33.3\%). This is similar to the findings of this study, where yellow globules, branching vessels, and decreased hair were seen in $50 \%$ of BT patients. In contrast, white areas were not observed in any of the lesions, but it should be noted that only 2 patients classified with BT leprosy were included. Other additional findings of yellow-brown structureless areas and coiled hairs were also encountered in $50 \%$ of BT patients.

Other studies have also described the dermoscopic findings in relation to the Ridley-Jopling classifications of leprosy. Common to all classifications are the presence of yellowish-orange structureless areas and linear branching vessels. The tuberculoid and borderline poles were found to be more commonly associated with loss of hair follicles and loss of eccrine duct openings, while the borderline lepromatous and lepromatous poles were more associated with xerosis, scaling and an accentuation of the normal reticular pigment network. ${ }^{9-11}$ In terms of clinical classifications, this study found no significant associations between the dermoscopic findings and Ridley-Jopling or WHO classifications. However, the majority of the patients included were multibacillary and lepromatous, thus robust conclusions about their associations cannot be made.

The finding of decreased hair was found to be significantly associated with treatment duration, with more newly treated patients (0-6 months) exhibiting decreased hair density. This may be due to the regrowth of hair in affected sites following leprosy treatment. ${ }^{20}$ The finding of decreased hair on dermoscopy, in association with structureless areas is considered a specific finding that can differentiate leprosy from other granulomatous diseases. ${ }^{9-11}$ During treatment, the number of dermal granulomas on histopathology may decrease, however, dermoscopic findings of structureless areas and globules were not found to be significantly associated with treatment duration. For average bacteriologic index, no dermoscopic findings were significantly associated.

Review of histopathological slides of 8 patients in whom selected lesions were biopsied following dermoscopy showed the presence of globules and structureless areas. These were indeed associated with the presence of granulomas in the 
papillary dermis, as mentioned in previous studies. ${ }^{5,16,18} \mathrm{We}$ tried to discern whether a nodular pattern or diffuse pattern of granulomatous infiltrates in the dermis would have different appearances on dermoscopy; however, no distinct association was observed.

The challenge in diagnosing leprosy is due to its varied clinical presentations, as evidenced by the wide range of dermoscopic findings in this study. These varied morphologic and dermoscopic presentations must also take into account the overall clinical context of the patient to enhance diagnostic accuracy. ${ }^{9}$ Dermoscopic findings can then serve as a valuable adjunct in accurately identifying this disease entity; however, its utility in terms of treatment monitoring remains to be demonstrated.

\section{CONCLUSION}

Since there is a paucity of reported dermoscopic findings in leprosy, this study aimed to gather a range of clinical presentations to assess whether distinct dermoscopic features can be associated with the different types and stages of leprosy to aid in diagnosis and treatment monitoring. While we were successful in gathering a variety of dermoscopic presentations, this study was limited by the relatively small sample size and a fewer number of paucibacillary and tuberculoid patients. In addition, since all dermoscopic images were reviewed by a single trained dermoscopist, the results may be prone to assessor bias.

For future studies, the inclusion of more newly diagnosed leprosy patients in whom simultaneous dermoscopy, biopsy, and slit skin smear can be done is recommended to be able to detect dermoscopic findings that could aid in the diagnosis of leprosy. Moreover, a longer study duration is recommended, with repeat of dermoscopy, biopsy and slit skin smear at predetermined time points along the course of treatment to be able to ascertain its value in monitoring response to treatment.

\section{Statement of Authorship}

All authors participated in the data collection and analysis and approved the final version submitted.

\section{Author Disclosure}

All authors declared no conflicts of interest.

\section{Funding Source}

No funding support.

\section{REFERENCES}

1. Walker SL, Lockwood DNJ. The clinical and immunological features of leprosy. Br Med Bull. 2006: 77-76;103-21. doi:10.1093/bmb/ld1010

2. World Health Organization. Expert Committee on Leprosy. Eighth Report. World Health Organ Tech Rep Ser. 2012; (968):1-61.

3. Handog EB, Gabriel MTG, Co CC. Leprosy in the Philippines: a review. Int J Dermatol. 2011; 50(5):573-81. doi:10.1111/j.13654632.2011.05044.x

4. Campos-do-Carmo G, Ramos-e-Silva M. Dermoscopy: basic concepts. Int J Dermatol. 2008; 47(7):712-9. doi:10.1111/j.13654632.2008.03556.x

5. Errichetti E, Stinco G. Dermoscopy in general dermatology: a practical overview. Dermatol Ther (Heidelb). 2016; 6(4):471-507. doi:10.1007/ s13555-016-0141-6

6. Russo T, Piccolo V, Lallas A, Argenziano G. Recent advances in dermoscopy. F1000Research. 2016; 5. doi:10.12688/f1000research. 7597.1

7. Ankad B, Sakhare P. Dermoscopy of histoid leprosy: a case report. Dermatol Pract Concept. 2017; 7(2):63-5. doi:10.5826/dpc.0702a14

8. Ankad BS, Sakhare PS. Dermoscopy of borderline tuberculoid leprosy. Int J Dermatol. August 2017. doi:10.1111/ijd.13731

9. Chopra A, Mitra D, Agarwal R, Saraswat N, Talukdar K, Solanki A. Correlation of dermoscopic and histopathologic patterns in leprosy - A pilot study. Indian Dermatol Online J. 2019; 10(6):663. doi:10.4103/ idoj.idoj_297_18

10. Vinay K, Kamat D, Chatterjee D, Narang T, Dogra S. Dermatoscopy in leprosy and its correlation with clinical spectrum and histopathology: a prospective observational study. J Eur Acad Dermatology Venereol. 2019; 33(10):1947-51. doi:10.1111/jdv.15635

11. Mohta A, Kumar Jain S, Agrawal A, (max of 6 authors), et al. Dermoscopy in leprosy: a clinical and histopathological correlation study. Dermatol Pract Concept. 2021; 11(2):e2021032. doi:10.5826/ dpc.1102a32

12. Acharya P, Mathur MC. Clinicodermoscopic study of histoid leprosy: a case series. Int J Dermatol. 2020; 59(3):365-8. doi:10.1111/ijd.14731

13. Mathur M, Acharya P, Karki A. Visual dermatology: crown vessels in dermoscopy of histoid leprosy. J Cutan Med Surg. 2019; 23(3):333. doi:10.1177/1203475419825759

14. Lavania RK, Girdhar A, Girdhar BK, Desikan K V. Histological changes in tuberculoid leprosy after fixed duration multidrug therapy for six months. Acta Leprol. 1990; 7(2):169-74.

15. Malathi M, Thappa DM. Fixed-duration therapy in leprosy: Limitations and opportunities. Indian J Dermatol. 2013; 58(2):93-100. doi:10.4103/0019-5154.108029

16. Lallas A, Argenziano G, Apalla Z, ( $\max$ of 6 authors), et al. Dermoscopic patterns of common facial inflammatory skin diseases. J Eur Acad Dermatology Venereol. 2014; 28(5):609-14. doi:10.1111/ jdv.12146

17. Pellicano R, Tiodorovic-Zivkovic D, Gourhant J-Y, (max of 6 authors), et al. Dermoscopy of Cutaneous Sarcoidosis. Dermatology. 2010; 221(1):51-4. doi:10.1159/000284584

18. Bombonato C, Argenziano G, Lallas A, Moscarella E, Ragazzi M, Longo C. Orange color: A dermoscopic clue for the diagnosis of granulomatous skin diseases. J Am Acad Dermatol. 2015; 72(1):S60-S63. doi:10.1016/j.jaad.2014.07.059

19. Thomas L, Phan A, Pralong P, Poulalhon N, Debarbieux S, Dalle S. Special locations dermoscopy. Dermatol Clin. 2013; 31(4):615-24. doi:10.1016/j.det.2013.06.006

20. Macedo R de B, Santos T, Ramos PBS, Takano DM, Leal VSM. Leprosy on the scalp. An Bras Dermatol. 2016; 91(5 suppl 1):69-71. doi:10.1590/abd1806-4841.20164391 